\title{
A NOTE ON RENAL FUNCTION IN SCARLET FEVER*
}

\author{
BORDEN S. VEEDER \\ ST. LOUIS \\ AND \\ MEREDITH R. JOHNSTON \\ Captain, M. C., U. S. Army
}

In almost all the studies of renal function in nephritis patients have been utilized in whom the nephritis was an established condition. A few experimental studies have attempted to correlate functional changes with the type of lesion produced by the injection into lower animals of nephrotoxic substances such as uranium or bacillary toxins, and to study in a comparative way the value of various functional tests. While making some functional tests in nephritis in the spring of 1915, it occurred to us that scarlet fever was a condition which offered an exceptional opportunity to study the functional renal changes in nephritis in the human being, from before the onset throughout the various clinical phases of the condition, with particular attention to the time relationship. There is no other disease in which nephritis is such a consistent and looked for complication.

Two types of nephritis must be distinguished in scarlet fever. Early in the course of the disease, in what may be termed the first stage, an acute nephritis, of an interstitial type pathologically, not infrequently develops as a part of the clinical picture of septic infection. This is distinct from the "febrile" albuminuria met with in a very large percentage of cases at the onset of the disease. It is a definite nephritis with casts and albumin in the urine, which, in its presence or absence and in its intensity, bears a direct relationship to the degree of sepsis. As a rule, it is mild in nature and disappears when the streptococcic infection is overcome, but when there is also a necrotic angina, or severe adenitis, or otitis, etc., the nephritis may be an important factor and the kidney shows marked lesions in fatal cases. In the second stage of scarlet fever, near the end of the third week of the disease, the well known "scarlatinal or "postscarlatinal" nephritis develops. The kidney shows extensive glomerular changes and the urine is scanty and contains quantities of albumin, casts and blood cells. Edema is common and uremia occasionally develops. There is no apparent relationship between the two types of nephritis. The first is best explained as a part of the streptococcic infection and the second

\footnotetext{
* From the Department of Pediatrics, Washington University School of Medicine.
} 
as the result of the toxins of the scarlet fever virus itself. In studying renal function in the nephritis of scarlet fever, the two types must be distinguished carefully, as renal function varies according to the type and degree of pathologic lesion present.

\section{REPORT OF CASES}

The two cases used in this study illustrate the two types.

CASE 1 (No. 9918).-A boy, aged 2 years, was admitted to the scarlet fever ward of the St. Louis Children's Hospital, March 11, 1916. From the very onset until death, March 18, the scarlet fever ran a severe septic course with the temperature never less than $102 \mathrm{~F}$, and at times as high as $106 \mathrm{~F}$. The throat was deeply ulcerated, and the tonsils and the mucous membranes of the nose and throat were covered with exudate from which cultures of streptococci were obtained. On the fifth day otitis developed in both ears. The lymph nodes became tremendously enlarged and suppuration took place. Prostration was marked and the patient was usually delirious, but no meningeal complication ensued. Abscesses developed at different points about the tenth day, and a terminal broncho-pneumonia complicated the picture. It was the typical picture of a severe septic infection. Early in the course of the illness the urine showed large quantities of albumin which persisted until the end, and coincidently pus cells and abundant casts appeared.

CASE 2 (No. 9600).-This patient, a boy, 4 years of age, had been at the country department for several months for general malnutrition. About April 11, 1916, he developed a mild scarlet fever with slight angina and adenitis. $\mathrm{He}$ was not at all prostrated and had a low fever for a few days. Until April 22 the urine was negative. On that day a trace of albumin was noted, and three days later a few casts were found. April 29 some edema appeared; the urine became scanty and a marked increase in the quantity of albumin was noted. Many casts and red blood cells were found microscopically. All the signs of the acute nephritis increased markedly during the next four days. A gradual improvement followed, slow at first but then with increasing rapidity, until by the end of one month only a trace of albumin and a few casts were left and no clinical sign of nephritis were present. Subsequently the urine cleared entirely.

\section{PLAN OF STUDY}

The plan of the study was as follows: Functional tests were to be made on admission. In septic cases with urinary changes these were to be repeated at frequent intervals. In mild cases, with a negative urine early in the course of the disease, weekly functional tests were to be made until either albumen appeared in the daily urine examination, or until any one of the functional tests showed a variation from the normal. The tests were then to be made at frequent intervals. In this way it might be expected to obtain information as to the curve of renal function in uncomplicated cases of scarlet fever, the curve of renal function in developing early and late types of nephritis, comparative data in regard to tests of retention and of excretion, and from these - most important - data as to time relations between functional changes as determined by retention or excretion tests and as shown by 
urinary changes. It was simply necessary to study a sufficient number of scarlet fever patients who were suitable for the tests, and sooner or later we would be bound to encounter cases of nephritis. The work was started in the fall of 1915 and continued whenever suitable material was available. It was by no means possible to utilize every patient with scarlet fever, and a large number had to be dropped after one or two of the weekly tests were made. The complete program was carried through in eight cases before one was encountered in which nephritis developed (Case 1), and in nine additional cases before a second case (Case 2) was found. Fortunately, they were frank and marked cases of their respective types. In this way data were collected on seventeen cases of uncomplicated scarlet fever and on two cases of scarlet fever with nephritis. The work was continued as material became available until the spring of 1917 , when all laboratory work was interrupted. As it is impossible to continue the work, it has seemed advisable to publish a note on the results so far obtained.

TABLE 1.-Results in Scarlet Fever Uncomplicated by Nephritis. Average for Seventeen Cases

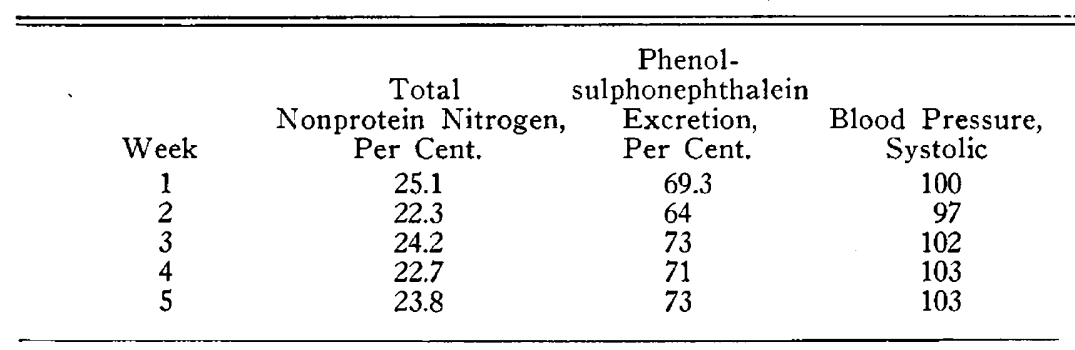

Tests for renal function, in addition to changes in the composition of the urine, are of two types. In one the ability of the kidney to excrete certain substances, such as dyes, is measured, and in the other the degree of retention or accumulation in the blood of substances normally excreted in the urine is ascertained. The phenolsulphonephthalein test was selected as an example of the first, and the total nonprotein nitrogen was taken as a test of retention. In addition, the blood pressure was determined by the auscultatory method.

\section{RESULTS}

In Table 1 the results obtained in the seventeen cases of scarlet fever uncomplicated with nephritis have been averaged. The tests for the first week represent tests made from the second to the fifth day of the disease, the second week from the tenth to the twelfth day, and so 
on. In all cases the diet was low in protein and creatinin free. The figures for the nonprotein nitrogen and the phenolsulphonephthalein are all within normal figures and quite uniform throughout the five weeks. Averaging blood pressure figures requires an explanation, as in the younger children the systolic pressure averaged about $90 \mathrm{~mm}$., and in the older $110 \mathrm{~mm}$. The important fact was the level at which the blood pressure remained throughout the course of the disease. This uniformity of figures for the average was maintained in each individual uncomplicated case.

The data for the two nephritic cases are shown in Table 2.

TABLE 2.-Results in Scarlet Fever Complicated by Nephritis Case 1, Early Interstitial Nephritis

\begin{tabular}{|c|c|c|c|c|}
\hline \multirow[t]{9}{*}{. } & $\begin{array}{c}\text { Week } \\
1 \\
2 \\
21 / 2\end{array}$ & $\begin{array}{cr}\text { Total } & \text { sulph } \\
\text { Nonprotein Nitrogen, } & \text { E } \\
\text { Per Cent. } & \\
29 & \\
34 & \\
47 & \text { Death }\end{array}$ & $\begin{array}{l}\text { Phenol- } \\
\text { onephthalein } \\
\text { ixcretion, } \\
\text { er Cent. } \\
52.5 \\
30 \\
?\end{array}$ & $\begin{array}{c}\text { Blood Pressure, } \\
\text { Systolic } \\
96 \\
94 \\
92\end{array}$ \\
\hline & & Case 2, Late Scarlatina & 1 Nephritis & . \\
\hline & $\begin{array}{l}\text { Date } \\
4 / 13\end{array}$ & 21.5 & 75 & 110 \\
\hline & $\begin{array}{l}4 / 22 \\
4 / 23\end{array}$ & $\underset{24.3}{\text { Albumin in urine }}$ & 60 & 108 \\
\hline & $\begin{array}{l}4 / 25 \\
4 / 27 \\
4 / 29\end{array}$ & $\begin{array}{c}\text { Casts in urine } \\
21 \\
\end{array}$ & 65 & 115 \\
\hline & $4 / 30$ & 39 & 60 & 115 \\
\hline & $\begin{array}{l}5 / 4 \\
5 / 6\end{array}$ & $\begin{array}{l}36.8 \\
39.3\end{array}$ & 60 & $1 \ddot{6} \dot{5}$ \\
\hline & $\begin{array}{l}5 / 9 \\
5 / 11\end{array}$ & $\begin{array}{l}29.8 \\
25.5\end{array}$ & $\ddot{60}$ & $\ddot{1} \ddot{3} \dot{8}$ \\
\hline & $5 / 23$ & 28.4 & 65 & 110 \\
\hline
\end{tabular}

In order to show the relative time relationship, Chart 1 has been prepared, in which the curve for the uncomplicated cases is shown by a solid line, the curve for fatal case of early interstitial nephritis is shown by the dotted line, and the curve of the glomerular scarlatinal nephritis is shown by a line of dashes.

In the early case there was rapid increase in the accumulation of nitrogenous substances in the blood from the very onset of the disease, and a corresponding decrease in the elimination of phenolsulphonephthalein. Blood pressure was relatively unaffected. 
The curve in Case 2, the glomerular type of nephritis, is more interesting. The first sign of urinary involvement was the appearance of albumin in the urine, this change being noted before any changes in the functional tests were manifest. Furthermore, the increase in the albumin and its disappearance from the urine corresponds with the development of the changes in the functional tests. Throughout the course of the disease the elimination of "phthalein" was not affected.

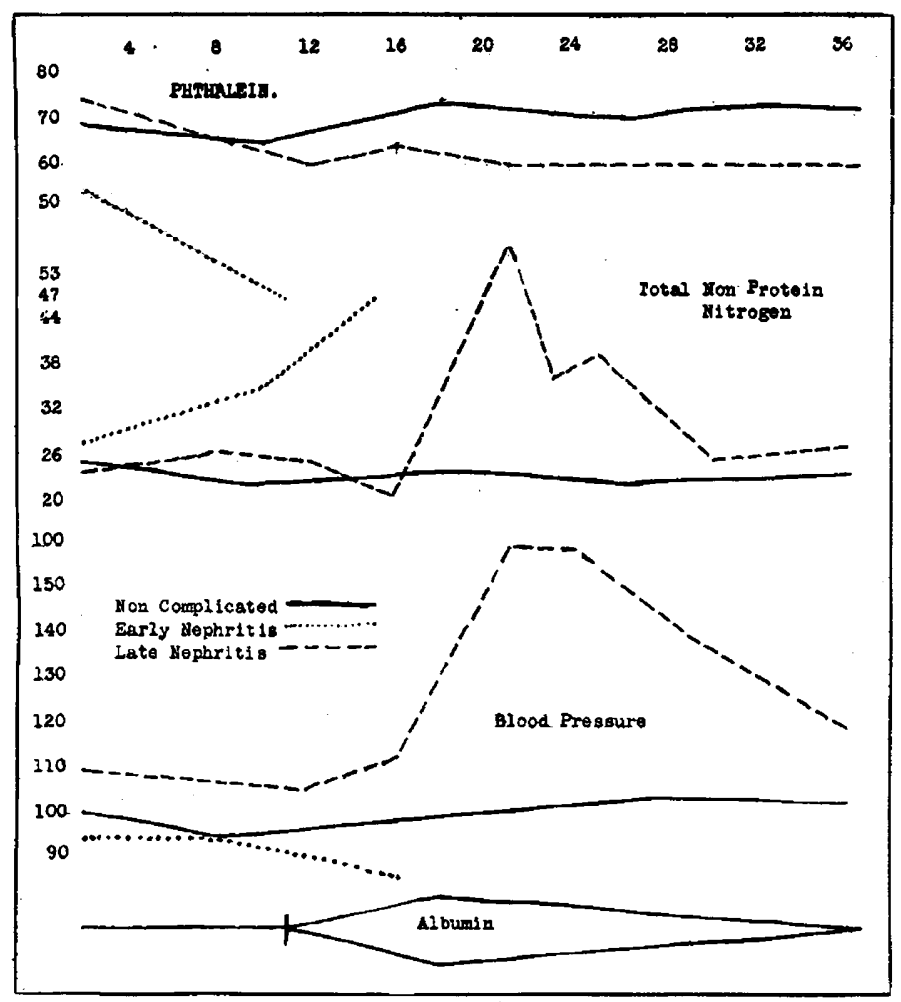

Time relationship in uncomplicated cases of scarlet fever and cases complicated by nephritis.

We have observed, however, in some other cases of post scarlatinal nephritis (established cases which were not followed through their development) a moderate decrease in the phthalein output at the height of the complications. Coincident with the development of the nephritis, a decided increase in the retention of the total nonprotein nitrogen took place. This retention was extremely rapid in development. The curve of increased blood pressure almost parallels the curve of nonprotein nitrogen retention. 
What is most important, in our opinion, is that although the functional changes, as noted, occur in the nephritis of scarlet fever and parallel in a fairly close way the urinary changes, the albumin appeared in the urine before the changes in renal function took place. Hence, as a routine measure, the urinary examination for albumin as ordinarily carried out in scarlet fever is of more value than the functional tests in announcing the onset of an impending kidney complication. 